\title{
Pemanfaatan Teknologi Informasi Untuk Meningkatkan Pelayanan Akademik Rumah Tahfidz dan TPQ Sakinah Cipayung Jakarta Timur
}

\author{
Hilda Amalia ${ }^{1}$ \\ Universitas Bina Sarana Informatika, hilda.ham@bsi.ac.id \\ Tri Retnasari2 ${ }^{2}$ \\ STMIK Nusa Mandiri , tri.trs@nusamandiri.ac.id \\ Susan Rachmawati ${ }^{3}$ \\ Universitas Bina Sarana Informatika, susan.srw@bsi.ac.id
}

\begin{abstract}
Abstrak
Perkembangan teknologi informasi yang terus berkembang setiap saat menghasilkan gaya hidup masyarakat yang selalu menginginkan kemudahan dan kecepatan dalam melakukan setiap transaksi dan mengakses informasi. Penggunaan teknologi informasi dalam setiap aspek kehidupan sangat diperlukan. Pemanfaatan Teknologi informasi dalam kegiatan operasional suatu organisasi menjadi hal yang harus dimiliki oleh setiap organisasi terutama organisasi yang bergerak dalam bidang pendidikan. Teknologi informasi merupakan alat yang dapat dimanfaatkan untuk peningkatan pelayanan institusi pendidikan. Dengan teknologi informasi semua data dapat diintegrasikan sehingga memudahkan kegiatan operasional organisasi sehingga mampu meningkatkan pelayanan organisasi bagi masyarakat. Salah satu pemanfaatan adalah sistem informasi akademik yang terintergrasi yang mampu menginformasikan perkembangan siswa yang ada di Rumah Tahfidz dan TPQ Sakinah sesuai dengan tujuannya yaitu menjadi lembaga pendidikan yang ingin terus berkembang menjadi lembaga pendidikan yang unggul serta mampu memberikan layanan pendidikan yang efektif dan efisien. Dengan adanya program kemitraan masyarakat maka diadakan kegiatan pembangunan website sistem informasi akademik bagi Rumah Tahfidz dan TPQ Sakinah dengan tujuan agar wali murid dapat dengan cepat mengetahui perkembangan anak-anak mereka selama belajar di rumah Tahfidz dan TPQ Sakinah. Aplikasi ini dirancang dengan menggunakan metode prototype yang bertujuan agar proses perancangan dah hasil akhir aplikasi yang dibuat dapat digunakan sesuai dengan kebutuhan.
\end{abstract}

\section{Kata Kunci: Teknologi Informasi, Akademik}

\begin{abstract}
The development of information technology that continues to develop at any time produces a lifestyle of people who always want the ease and speed of doing every transaction and accessing information. The use of information technology in every aspect of life is very necessary. Utilization of information technology in the operational activities of an organization must be owned by every organization, especially organizations engaged in the field of education. Information technology is a tool that can be used to improve the services of educational institutions. With information technology all data can be integrated so as to facilitate the operational activities of the organization so as to improve organizational services
\end{abstract}


for the community. One of the uses is an integrated academic information system that is able to inform the development of students in the Tahfidz and TPQ Sakinah Homes in accordance with its goal of being an educational institution that wants to continue to develop into a superior educational institution and able to provide effective and efficient education services. With the community partnership program, an academic information system website development activity was held for Rumah Tahfidz and TPQ Sakinah with the aim that students' parents could quickly find out about their children's development while studying at Tahfidz and TPQ Sakinah's house.

\section{Keywords: Information Technology, Academic}

\section{Pendahuluan}

Perkembangan teknologi informasi menuntut masyarakat dan para pelaku bisnis untuk menggunakannya dan terus meningkatkan penggunaannya sehingga dapat memberikan dampak positif bagi setiap penggunanya. Pemanfaatan teknologi informasi digunakan hampir di seluruh bidang kehidupan seperti bidang pendidikan, kesehatan, bisnis dan manajemen, pertanian dan peternakan, penambangan, pertahanan dan keamanan serta bidang transportasi (Sanmorino, 2017). Dengan teknologi informasi memudahkan kita mendapatkan informasi yang kita inginkan (Mubarok, et al., 2018). Sistem informasi adalah suatu sistem yang mempertemukan kebutuhan pengolahan transaksi harian untuk mendukung aktivitas operasional transaksi harian mapupun untuk kegiatan strategis yaitu menghasilkan laporan yang berisi mengenai informasi bagi pihak yang berkepentingan (Aswanti, Mulyani, Siagian, \& Syah, 2015). Di dunia pendidikan diperlukan sistem informasi akademik yang digunakan untuk memudahkan proses pengolahan data siswa, guru dan menghasilkan laporan akademik. Sistem informasi akademik adalah suatu sistem yang dirancang untuk mengelola data-data akademik sehingga memudahkan untuk pengguna dalam kegiatan administrasi akademik secara online (Djaelangkara, Sengkey, \& Antang, 2015). Dengan dibangunnya sebuah website bagi sekolah dapat memudahkan masyarakat dan warga sekolah untuk mendapatkan informasi mengenai sekolah (Akbar \& Tjendrowaseno, 2015) Mitra dalam pengabdian kepada masyarakat pada kali ini adalah Rumah Tahfidz dan TPQ Sakinah. Rumah Tahfidz dan TPQ Sakinah berkomitmen untuk menyelenggarakan pendidikan yang bisa mengantarkan santri menjadi penghafal qur'an sehingga mampu menerapkan ilmunya dalam kehidupan sehari-hari dan juga mampu meraih prestasi. Peningkatan pelayanan ini dibutuhkan untuk Rumah Tahfidz \&TPQ Sakinah agar terus mampu memberikan pelayanan yang terbaik dan bersaing dengan Rumah Tahfidz \& TPQ lainnya. Pada saat ini Rumah Tahfidz \& TPQ Sakinah mengalami kesulitan dalam mengolah data santri dan melihat perkembangan pendidikan santri, untuk itu perlu dibangun suatu sistem informasi akademik yang mampu menghasilkan laporan perkembangan siswa secara cepat, mengelola data santri agar lebih terstruktur serta mempermudah pengajar dan orangtua dalam memonitor perkembangan setoran hafalan santri.

\section{Metode}


Pelaksanaan PKM akan dilakukan oleh tim pelaksana yang terdiri dari tiga orang dosen dan mahasiswa, yaitu ketua dari dosen Falkultas Teknologi dan Informatika Universitas Bina Sarana Informatika dan satu anggota dari Falkultas Teknologi Informasi STMIK Nusa Mandiri Jakarta dan satu anggota dari Falkultas Akuntansi Universitas Bina Sarana Informatika, serta partisipasi dari guru dan manajemen Rumah Tahfidz dan TPQ Sakinah. Mitra mengalami kesulitan dalam mengolah data santri dan membuat laporan secara berkala untuk mengetahui perkembangan pendidikan santri kepada wali murid santri. Untuk itu tim dosen membuatkan sistem informasi akademik sehingga wali murid lebih mudah melihat laporan perkembangan santri dan laporan perkembangan dapat terdokumentasi dengan baik. Metode pelaksanan dalam kegiatan pengabdian ini adalah pendampingan, pelatihan dan simulasi atau sosialisasi mengenai penggunaan sistem informasi akademik Rumah tahfidz dan TPQ Sakinah.

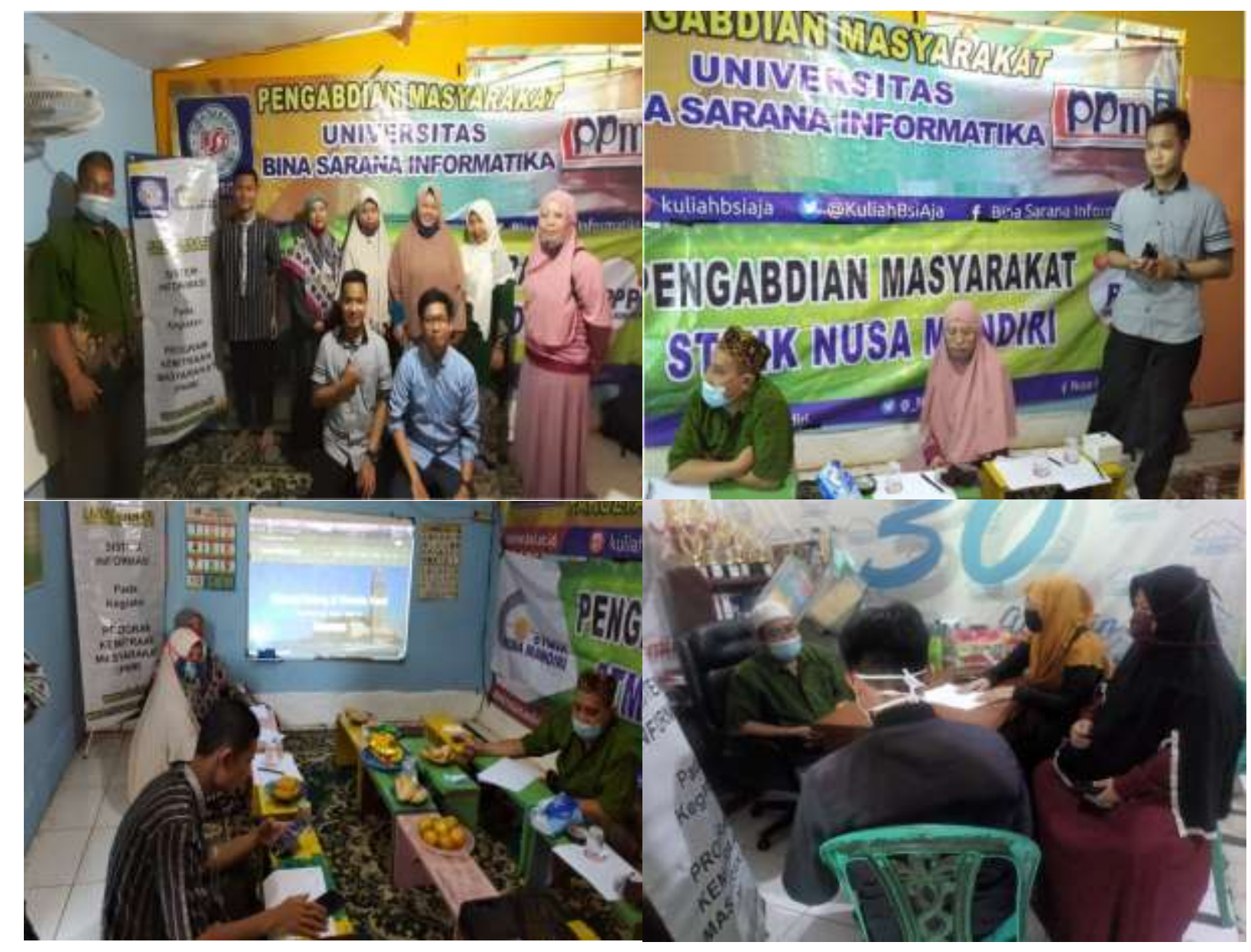

Gambar 1. Pelaksanaan Kegiatan Pelatihan Pengabdian Masyarakat

\section{Hasil dan Pembahasan}

Pengabdian masyarakat dilaksanakan pada tanggal 28 Juni 2020. Dalam pelaksanaan pengabdian masyarakat ini dilaksanan dengan metode pendampingan, 
pelatihan dan simulasi. Adapun tahapan metode prototipe meliputi investigasi awal, analisis masalah, analisis kebutuhan sistem, pembuatan database dan perancangan

1. Dimulai dengan dilakukannya komunikasi antara tim pengembang dengan pihak manajemen Rumahtahfidzdan TPQ Sakinah.

2. Tim pengembang bertemu dengan stakeholder untuk mendefinisikan sasaran, mengidentifikasi spesifikasi kebutuhan.

3. Pembuatan prototipe direncanakan dengan cepat, dan pemodelan dilakukan.

4. Di lakukan evaluasi terhadap prototipe yang telah dibuat.

5. Setiap tahapan proses pengembangan sistem dapat diulang jika terdapat kekurangan atau kebetuhan dari pihak manajemen Rumah Tahfidzdan TPQ Sakinah.

Dalam pembuatan website sistem informasi akademik Rumah Tahfidz dan TPQ Sakinah dirancang struktur navigasi yang akan menjadi dasar pengembangan dari sistem informasi akademik untuk Rumah Tahfidz dan TPQ Sakinah. Struktur navigasi berisi menu-menu yang ada pada website dan alur kerja dari website. Menu-menu yang dibangun berdasarkan analisis kebutuhan dari Rumah Tahfidz dan TPQ Sakinah.

1. Desain Struktur Navigasi Website Rumah Tahfidz \& TPQ Sakinah

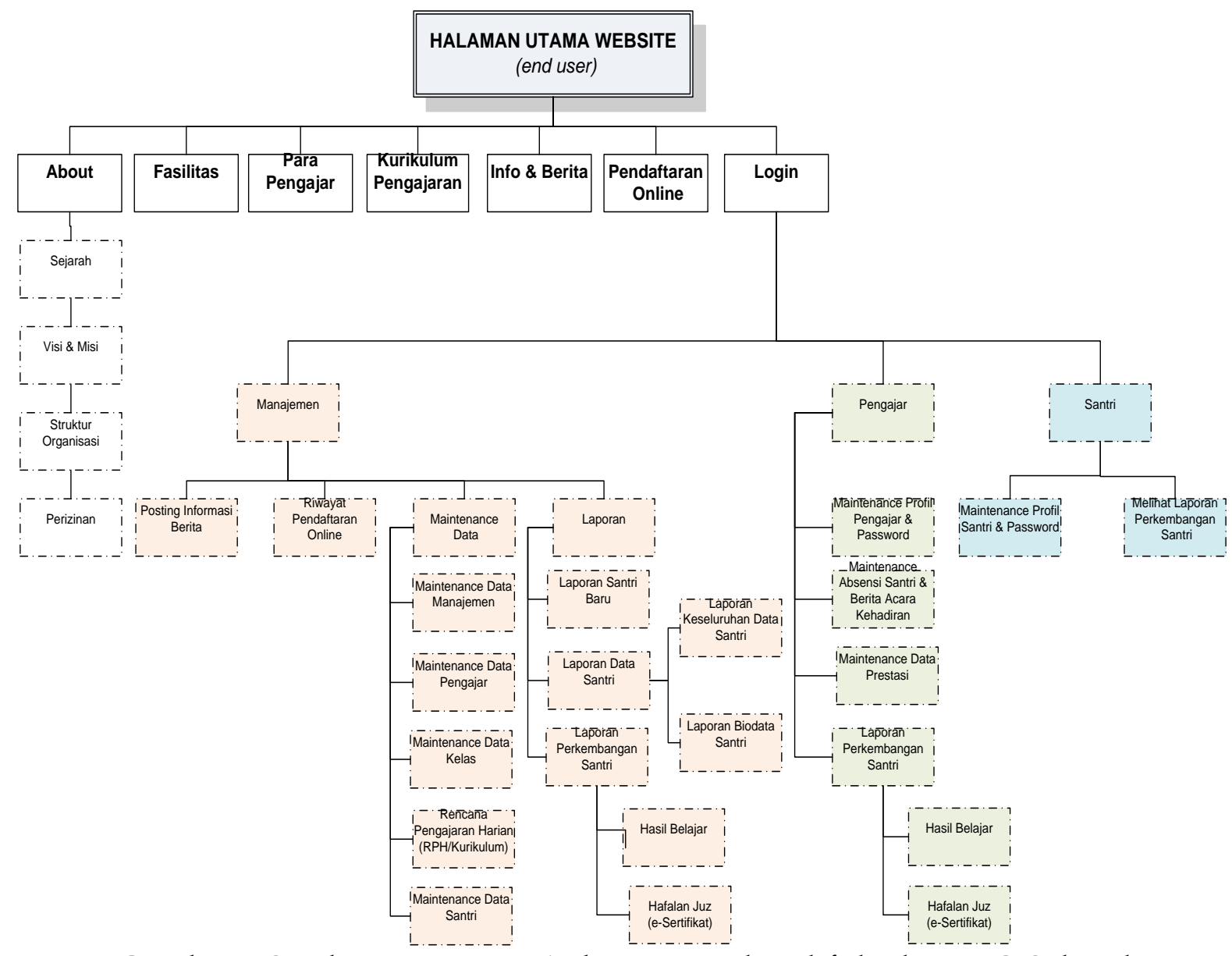

Gambar 1 Struktur Navigasi Website Rumah Tahfidz dan TPQ Sakinah 
Gambar 1 menunjukan menu-menu dan alur kerja dari setiap menu yang ada pada website Rumah Tahfidz dan TPQ Sakinah. Di halaman utama website disedia tujuh menu yaitu About, Fasilitas, Para Pengajar, Kurikulum Pengajaran, Info dan Berita, Pendaftaran dan Login. Terdapat tiga jenis pengguna dari sistem informasi akademik Rumah tahfidz dan TPQ Sakinah yang dapat login ke dalam website. Pengguna tersebut adalah manajemen yang dapat mengelola data master dan transaksi yang ada. Penggajar atau guru yang dapat melakukan absensi siswa atau santri dan menginput perkembangan harian siswa. Serta santri dalam hal ini diwakili oleh orang tua atau wali santri untuk dapat login dan melihat informasi mengenai berita acara perkembangan santri setiap harinya.

\section{Tampilan Antar Muka Website Tahfidz dan TPQ Sakinah Cipayung}

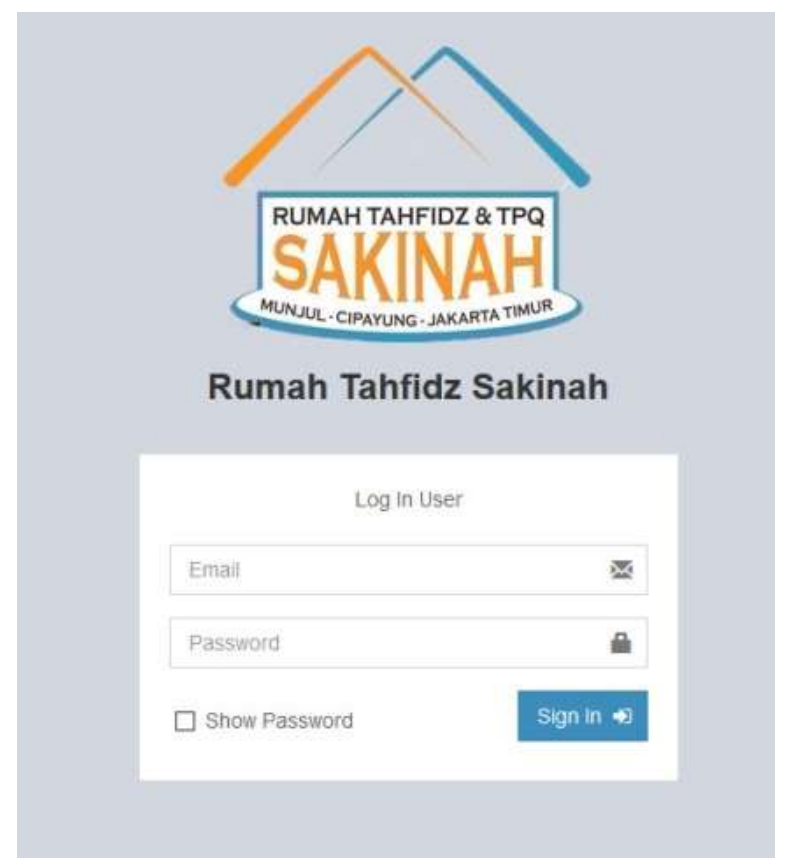

Gambar 2 Tampilan Antar Muka Menu Login

Gambar 2 menampilkan tampilan layar dari menu login untuk semua user yang dapat menggunakan sistem. Sebelum user dapat menggunakan sistem harus didaftarkan dulu oleh user admin atau user manajemen untuk mendapatkan email login dan password yang dapat digunakan. 


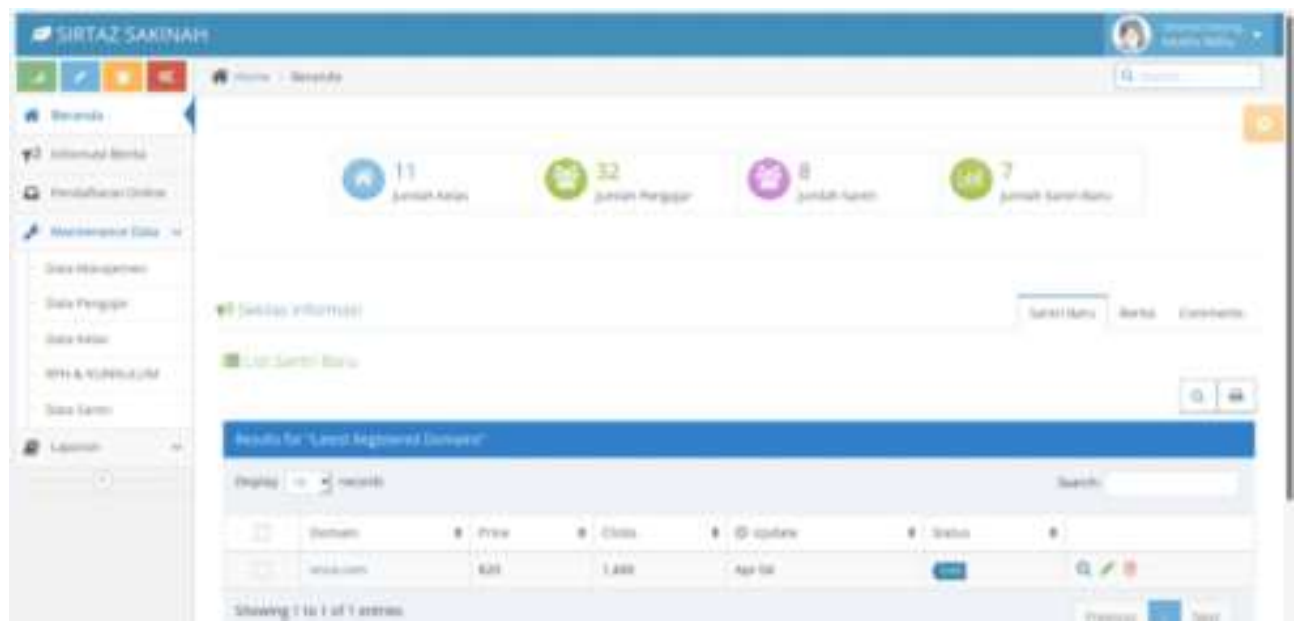

Gambar 3. Tampilan Layar Dashboard Manajemen

Gambar 3 merupakan tampilan antar muka dashboard manajemen, tampilan ini merupakan tampilan yang muncul ketika user manajemen melakukan login ke halaman website.

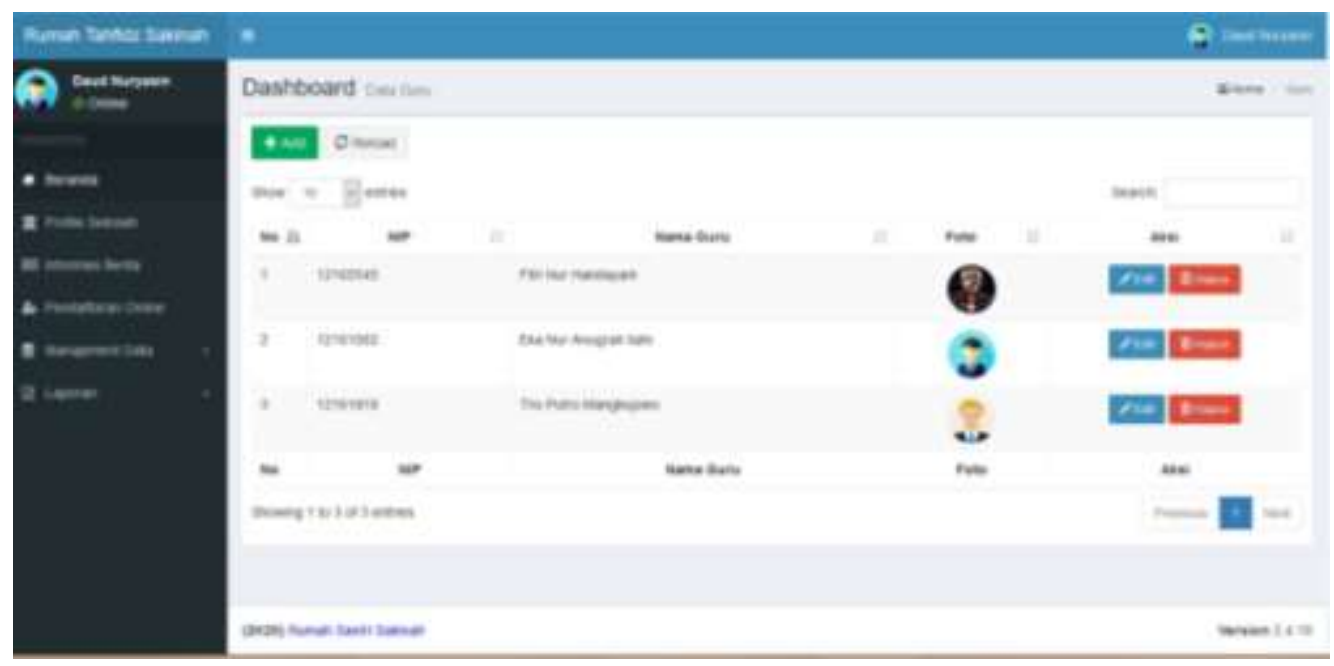

Gambar 4 Tampilan Antar Muka Menu mengelola Data Guru

Gambar 4 merupakan tampilan antar muka menu mengelola data guru, user manajemen atau admin dapat melakukan input, edit dan hapus data guru. 


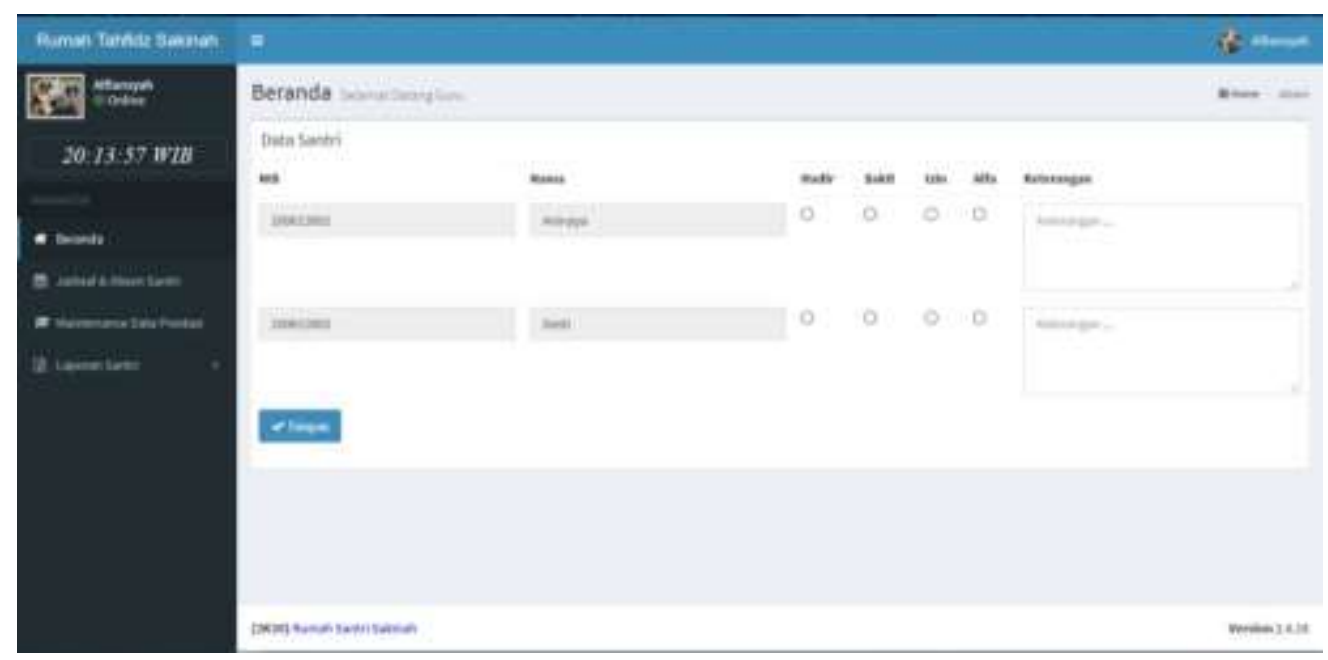

Gambar 5 Tampilan Antar Muka Menu Absensi

Gambar 5 merupakan tampilan antar muka menu absensi, pada menu absensi ini guru mengabsen siswa atau santri kemudian memberikan keterangan mengenai prestasi harian yang dikerjakan oleh siswa atau santri setiap harinya.

\section{Simpulan dan Rekomendasi}

Kegiatan PKM ini berjalan lancar sampai akhir acara dan disambut dengan baik oleh mitra yaitu Rumah Tahfidz dan TPQ Sakinah. Dengan menggunakan sistem informasi akademik diharapkan dapat mempercepat proses pengolahan data, penyimpanan data, informasi ke publik atau umum sampai dengan proses pembuatan laporan sehingga waktu yang dibutuhkan untuk mengolah data tersebut relatif lebih singkat. Pihak mitra yaitu Rumah Tahfidz dan TPQ Sakinah sangat mengapresiasi adanya sistem informasi akademik yang dapat mendukung pengolahan data master, nilai kehadiran hingga menampilkan laporan yang dibutuhkan, serta sistem yang mendukung adanya hak akses. Bagi Orangtua/Wali santri dengan adanya sistem informasi akademik lebih cepat dan akurat untuk memantau atau memonitoring perkembangan akademik anaknya selama melakukan proses belajar mengajar di Rumah Tahfidz dan TPQ Sakinah.

\section{Acknowledgments}

Penelitian dibiayai oleh Direktorat Riset dan Pengabdian Masyarakat Deputi Bidang Penguatan Riset dan Pengembangan Kementrian Riset dan Teknologi/Badan Riset dan Inovasi Nasional sesuai dengan Kontrak Pelaksanaan Program Kegaitan Pengabdian Kepada Masyarakat Nomor 100/SP2H/PPM/DRPM/2020 tanggal 16 Maret 2020

\section{Daftar Pustaka}

Akbar, G., \& Tjendrowaseno, T. I. (2015). Website Profile Sekolah sebagai Media Informasi dan Promosi. Indonesia Jurnal on Networkingand Security, 34-38. 
Aswanti, S., Mulyani, N., Siagian, Y., \& Syah, A. Z. (2015). Peranan Sistem Informasi Dalam perguruan Tinggi. Jurnal Teknologi dan Sistem Informasi, 79-86.

Djaelangkara, R. T., Sengkey, R., \& Antang, O. (2015). Perancangan Sistem Informasi akademik Sekolah Berbasis Web studi Kasus Sekolah Menengah Ataa Kristen 1 Tomohon. Jurnal Elektro dan Komputer, 86-94.

Mubarok, A., Riana, D., Sanjaya, R., Prasetyo, R. T., Ramadhani, Y., Rismayadi, A. A., et al. (2018). Sistem Informasi Pelayanan Online di Mapolresta Bandung. JURNAL ABDIMAS BSI, 1-6.

Sanmorino, A. (2017). Pemanfaatan Teknologi Informasi Berupa Web Based Application Pada Sektor usaha Kecil dan Menengah. JURNAL ABDIMAS MANDIRi, 7-13. 